\title{
Patient positioning during minimally invasive surgery: what is current best practice?
}

This article was published in the following Dove Press journal:

Robotic Surgery: Research and Reviews

14 July 2017

Number of times this article has been viewed

\section{Jacqueline M Zillioux \\ Tracey L Krupski}

Department of Urology, University of Virginia, Charlottesville, VA, USA
Correspondence: Tracey L Krupski Department of Urology, University of Virginia, 1215 Lee Street, Charlottesville, VA 22908, USA

Tel +l 4349240042

Email Tlk6f@virginia.edu
Introduction: Positioning injuries are a known surgical complication and can result in significant patient morbidity. Studies have shown a small but significant number of neurovascular injuries associated with minimally invasive surgery, due to both patient and case-specific factors. We sought to review the available literature in regards to pathophysiological and practical recommendations.

Methods: A literature search was conducted and categorized by level of evidence, with emphasis on prospective studies. The result comprised 14 studies, which were summarized and analyzed with respect to our study objectives.

Results: While incidence of positioning injury has been identified in up to one-third of prospective populations, its true prevalence after surgery is likely $2 \%-5 \%$. The mechanism is thought to be intraneural disruption from stretching or pressure, which results in decreased perfusion. On a larger scale, this vascular compromise can lead to ischemia and rhabdomyolysis. Prevention hinges on addressing patient modifiable factors such as body mass index, judicious positioning with appropriate devices, and intraoperative team awareness consisting of recurrent extremity checks and time management.

Conclusion: The risk for positioning injuries is underappreciated. Surgeons who perform minimally invasive surgery should discuss the potential for these complications with their patients, and operative teams should take steps to minimize risk factors.

Keywords: positioning, neuropraxia, minimally invasive, robotic-assisted, injury, peripheral neuropathy

\section{Introduction}

Injury resulting from patient positioning is a known perioperative risk and a significant contributor to patient morbidity. These complications can range from transient peripheral neuropathies to compartment syndrome and rhabdomyolysis. There exists no comprehensive data on the incidence and costs though the American Society of Anesthesiologists Closed Claims study offers a glimpse: peripheral nerve injury, which represents just a subset of positioning injuries, made up $15 \%$ of claims across surgical disciplines. ${ }^{1,2}$

Positioning injuries are recognized in open surgery, but laparoscopic surgery appears to incur increased risk. Pelvic surgery, both open and laparoscopic, has risk of neurologic injury due to improper placement of retractors, autonomic nerve disruption from surgical dissection and improper lithotomy positioning. ${ }^{3}$ A 2014 retrospective review of robotic-assisted surgeries found a $6.6 \%$ injury rate, suggesting robotic surgery may further increase risk. 
Nevertheless, the perception among many surgeons is that positioning injuries are rare events that "don't happen at our institution". This paper attempts to summarize what is known about the problem and offers insight on preventive measures and best practices.

\section{Methods}

Our goal was to scour the available literature with the following two broad aims. First, we sought to report on the incidence/prevalence of injuries and provide the theorized mechanisms of injury for understanding the pathophysiology. Second, we wanted to provide practical guidance on risk factors and prevention.

We initially undertook a literature search of PubMed and Ovid medical databases. The search terms utilized included: positioning, injury, peripheral neuropathy, nerve injury, compartment syndrome, rhabdomyolysis, ischemic optic neuropathy, laparoscopic, robotic, and surgery in varied combinations. The search criteria and selection of articles are depicted in Figure 1.
We limited the search to English language and screened for observational cohort, meta-analyses, and trials. No metaanalyses, systematic reviews or randomized controlled trials were found. Case series and surveys were excluded. Initial inspection found several articles that reported on surgeoninduced operative injury to nerves and we elected to remove these, as the mechanism of injury was different. Thus, our search returned 14 articles. We did identify six prospective cohort (observational) studies, six retrospective reviews, and two retrospective population-based review studies. The last search date was March 5, 2017. We categorized our results by surgical specialty and summarized them in Table 1, providing information on approach, sample size, and type of injury. Interestingly, these specialties are limited to the pelvis.

\section{Results}

\section{Pathophysiology - incidence}

Most of the identified studies assessed postoperative neuropathies, reporting rates of $0.8 \%-6.6 \%$ for robotic and $0.10 \%-3.2 \%$ for laparoscopic surgeries. Excluding Ulm

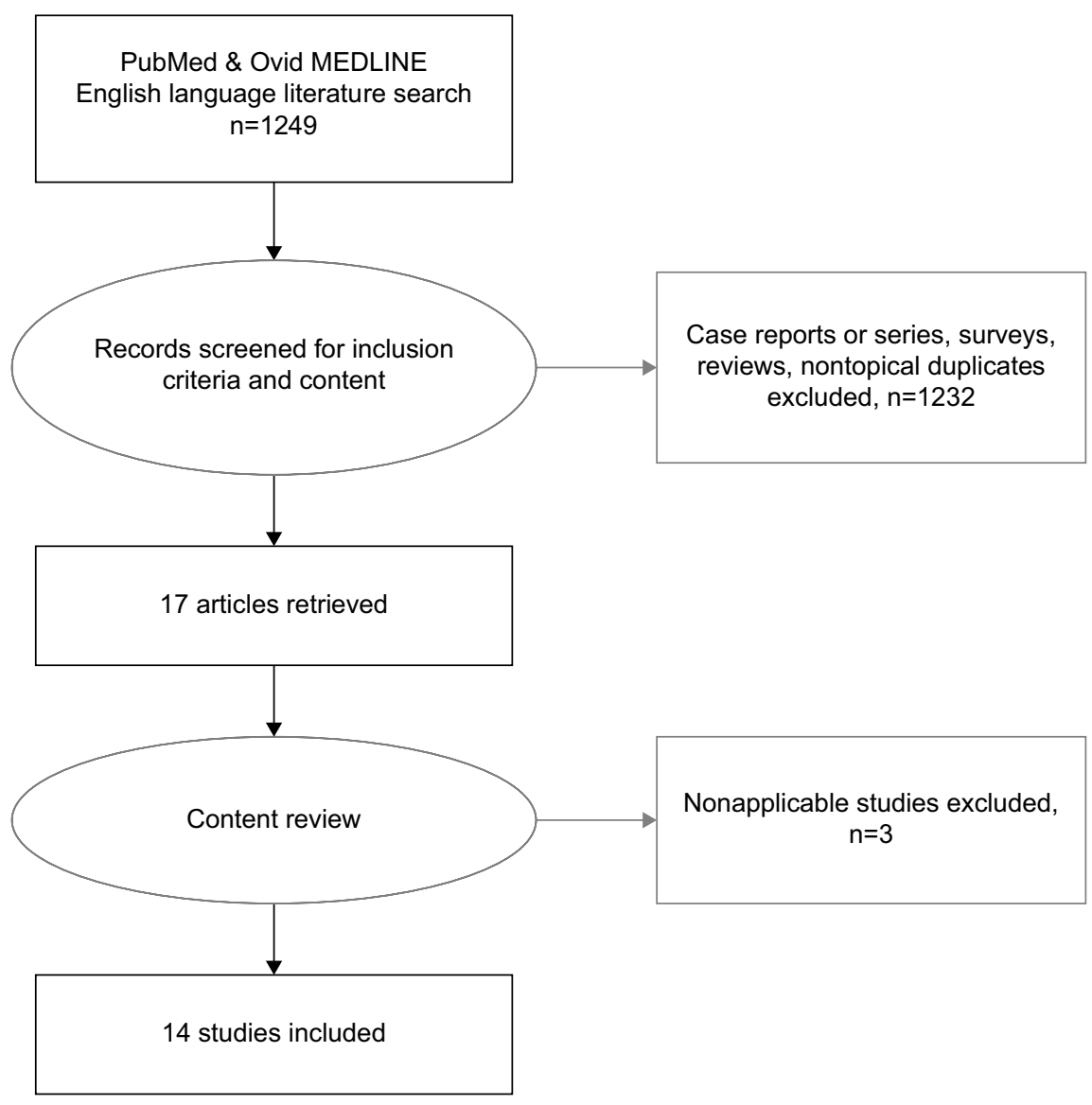

Figure I Flow chart of literature search. 
Table I Summary of literature search, including sample size and type of injury

\begin{tabular}{|c|c|c|c|c|c|c|c|}
\hline Subspecialty & First author & Year & Design & Approach & $\mathbf{N}=$ & Positioning injury studied & $\begin{array}{l}\text { Incidence, } \\
\%\end{array}$ \\
\hline \multirow[t]{8}{*}{ Gynecology } & Bohrer et al ${ }^{49}$ & 2009 & PC & Robot, Lap & 616 & Lower extremity neuropathy & 1.8 \\
\hline & Ulm et $\mathrm{al}^{35}$ & 2014 & PC & Robot & 831 & Neuromuscular & 0.8 \\
\hline & Wolf et a $\left.\right|^{50}$ & 2000 & $R R$ & Lap & 1651 & Neuromuscular & 2.7 \\
\hline & Jeong et $\mathrm{a}^{51}$ & 2010 & RR & Robot & 200 & Peripheral neuropathy & 1.5 \\
\hline & Koc et $\mathrm{al}^{15}$ & 2012 & $\mathrm{RR}$ & Robot* & 377 & Lower extremity neuropathy & 1.3 \\
\hline & Mattei et al ${ }^{52}$ & 2013 & PC & Robot & 60 & Neuromuscular & 35 \\
\hline & Pridgeon et $\mathrm{a}^{28}$ & 2013 & $\mathrm{RR}$ & Robot & 3110 & Compartment syndrome & 0.3 \\
\hline & Wen et al ${ }^{29}$ & 2014 & RPB & All & 175,699 & Peripheral neuropathy & 0.16 Robot \\
\hline \multirow[t]{7}{*}{ Urology } & & & & & & & 0.10 Other \\
\hline & & & & & & Compartment syndrome & 0.07 \\
\hline & Di Pierro et $\mathrm{a}^{32}$ & 2014 & PC & Robot & 233 & Neuromuscular & $7-31.0$ \\
\hline & Mills et $\mathrm{al}^{34}$ & 2014 & $\mathrm{RR}$ & Robot & 331 & Peripheral neuropathy & 6.6 \\
\hline & Gelpi- & 2016 & RPB & All & 550,430 & Rhabdomyolysis & 2.43 OR for \\
\hline & $\begin{array}{l}\text { Hammerschmidt } \\
\text { et } \mathrm{a}^{31}\end{array}$ & & & & & & Robot vs Lap \\
\hline & $\begin{array}{l}\text { Navarro-Vincete } \\
\text { et al }{ }^{36}\end{array}$ & 2011 & PC & Lap, Open & 2304 & Peripheral neuropathy & 3.2 Lap \\
\hline \multirow[t]{5}{*}{ Colorectal } & & & & & & & 0.2 Open \\
\hline & Eteuati et $\mathrm{a}^{37}$ & 2013 & PC & Lap & 548 & Brachial plexus neuropathy & 0.9 \\
\hline & Velchuru et $\mathrm{a}^{33}$ & 2014 & RR & All & 1111 & Peripheral neuropathy & 3.6 Robot \\
\hline & & & & & & & I.7 Lap \\
\hline & & & & & & & 0.2 Open \\
\hline
\end{tabular}

Note: *Used split leg table.

Abbreviations: Lap, laparoscopic; OR, odds ratio; PC, prospective cohort; RPB, retrospective population-based; RR, retrospective review.

et al review of a prospectively gathered database demonstrating just $0.8 \%$ rate of positioning neuromuscular injuries in robot-assisted gynecologic surgeries, studies across the board suggest higher rates of positioning injury in robotic compared to laparoscopic surgery.

As shown in Table 1, the term positioning injury is amorphous and comprises several clinical conditions. One such complication, brachial plexus injury, has been described in association with laparoscopic surgery since 1993, but injuries associated with the elbow and popliteal fossa compression and compartment syndromes represent the bulk of the literature. ${ }^{4}$ Nonetheless, unique injuries such as perioperative visual loss also exist and are postulated to arise from similar causes. ${ }^{5}$ Summary statement: transient neurologic insults occur in almost one-third of patients, but the actual incidence of positioning injuries appears to be in the range of $2 \%-5 \%$.

\section{Pathophysiology - underlying mechanism}

Pelvic surgery, whether laparoscopic or robotic, requires the patient to not only be placed in stirrups, but also often positioned in the Trendelenburg position for part, if not all, of the time of surgery. Both of these increase the potential for stretch injuries. There appears to be a complex interplay of neurologic and vascular insults that result from prolonged pressure or stretch on an affected area. The exact basic science behind the impairment is controversial. Experts have described that stretching of a nerve may cause disruption of the blood vessels running intraneurally, which leads to decreased perfusion. ${ }^{6}$

If the intraneural connective tissue tears, this can result in intraneural hemorrhage and possibly lead to necrosis. Nerves lying over a firm protuberance, such as the peroneal or ulnar nerves, can be especially at risk for stretching that leads to compression of the nerve at the protuberance. ${ }^{6}$ The mild compression that occurs most commonly results in only temporary interruption of conduction and is thus reversible within minutes after reperfusion. The concept of endoneural edema has been proposed as the mechanism behind more severe compression or stretching of a nerve, whereby the nerve experiences elevated intraneural pressures. ${ }^{8}$ The high pressures can affect axoplasmic flow, leading to impairment that can last for hours to weeks. Extremely long compression with more edema leads to demyelination or segmental degeneration. ${ }^{7}$ Function does not return until the axons regrow along the degenerated segment. Studies have suggested that this occurs at a growth rate equal to roughly $1 \mathrm{~mm} /$ day, and increases in more distal injuries; but in rare circumstances, the injury may be so severe that it precludes regrowth. ${ }^{6,8}$

While nerve stretch and pressure injuries involve intraneural vascularity as described above, compartment syndrome is 
a primarily vascular-mediated damage on a larger scale. The oxygen saturation of tissues within muscle has been studied at a basic science level. ${ }^{9} 10$ The deep muscle mixed tissue oxygen saturation within the gastrocnemius has been measured during laparoscopic pelvic surgery. ${ }^{9}$ The tissue was found to be hypoxic and the authors postulated that a combination of hydrostatic forces, lower blood pressure, and intra-abdominal pressure led to tissue underperfusion. Similarly, a decrease in mean ankle pressure resulted when patients were placed in steep Trendelenburg and lithotomy positions. ${ }^{10}$ This decrease in perfusion was quantified as $0.78 \mathrm{mmHg}$ decrease in arteriolar pressure for every centimeter of ankle height above the right atrium. Once the perfusion pressure goes down, cellular swelling occurs, compressing capillary vessels and compromising venous outflow. When the ankles are lowered, reperfusion injury may subsequently occur. ${ }^{11}$

Additional concerns may exist for robotic-assisted surgery (RAS). Safety of RAS has increasingly been in news due to the permeation of the da Vinci surgical system into health systems across the country. ${ }^{12}$ Historically, RAS has been marketed as providing great advantage in visualization and reconstruction in the deep pelvis, resulting in rapid uptake by gynecologic and urologic oncologists; but market forces and patient demand have expanded the use to almost every surgical subspecialty. ${ }^{13,14}$ Distinctive positioning is required for pelvic minimally invasive surgery, including steep Trendelenburg $\left(30^{\circ}-40^{\circ}\right)$ and docking of the robot from between the legs. This position may be sustained longer for RAS, particularly early in the learning curve. This position allows the bowels to fall toward the head and the retroperitoneum for the pelvis to be accessed while maintaining full mobility of the robot arms. To accommodate the robot from the caudal position, either lithotomy position with stirrups or a split leg table is needed. Both operative maneuvers have the potential for compression injury. ${ }^{15}$ Figure 2A demonstrates Allen stirrups and Trendelenburg positioning with the head below the pelvis and Figure 2B demonstrates a split leg table.

A

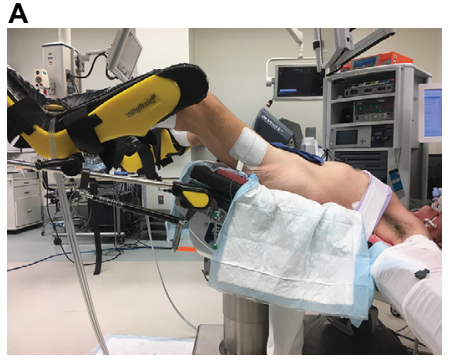

B

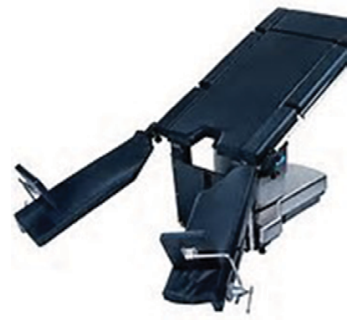

Figure 2 (A) Allen stirrups used with steep Trendelenburg position; (B) split leg table.
The steep Trendelenburg position used in pelvic RAS increases the risk of sustaining two distinct injuries: brachial plexus neuropathy and ischemic optic neuropathy (ION). The former is one of the more common postoperative neuropathies. ${ }^{1}$ A steep downward angle may allow the patient's head and shoulders to slip toward the head of the table intraoperatively. Although the patient's shoulder and neck may be placed in an appropriately neutral position at induction, downward slipping during the case can lead to hyperabduction of the arm, resulting in stretch of the brachial plexus. In some cases, compression on the plexus by the humerus and clavicle or first rib leads to injury as well. ${ }^{6} 16$ Efforts to prevent movement with shoulder braces or wristlets have only increased the risk of stretch and compression injury to the brachial plexus. ${ }^{17}$

A less common, but potentially more catastrophic, risk of steep Trendelenburg position is ION. This complication is manifested as blurred or lost vision postoperatively and carries poor prognosis. ${ }^{18}$ Traditionally, it has been associated with protracted surgeries complicated by severe hypotension or blood loss. The hypoperfusion leading to ION in the head down position is thought to be due to a combination of venous stasis, increased intraocular pressure, and facial edema. ${ }^{19}$ In laparoscopic and robotic surgery, increased arterial $\mathrm{CO}_{2}$ from resorbed pneumoperitoneum is thought to lead to choroidal vasodilation and thus further increases intraocular pressure. ${ }^{20}$ There have been just four case reports in the robotic-assisted radical prostatectomy (RALP) literature. ${ }^{21}$ However, there is convincing evidence that long operations in steep Trendelenburg position carry significant increased risk of ION compared to supine. Awad et al demonstrated that steep Trendelenburg position is associated with a doubling of intraocular pressures compared to the supine position, and Hoshikawa et al demonstrated that this increase in ocular pressure is time-dependent ..$^{20,22}$

Lithotomy position is another pelvic RAS requirement that incurs well-documented positioning injury risks, primarily of lower extremity peripheral neuropathies and compartment syndrome. For endoscopic urologic and simple gynecologic procedures performed in lithotomy, the operative time is usually $<1$ hour. However, with the advent of major extirpative RAS procedures, the time in lithotomy can be over 3 or 4 hours when docking, obtaining pneumoperitoneum, surgical and undocking times are factored in. This necessitates more time for lower extremity nerves to be compressed or for hypoperfusion to occur.

The most common lower extremity neuropathy related to lithotomy position is of the common peroneal nerve, 
resulting from compression of the nerve between the fibular head and the stirrup. Likewise, the saphenous nerve may be compressed at the medial tibial condyle. ${ }^{23,24}$ The femoral cutaneous nerve and obturator nerves can be injured from hyperabduction and hyper-extension in lithotomy. ${ }^{25}$

As described above in the mechanism section, stirrups require the ankles to be above the heart. In combination with Trendelenburg, perfusion to lower limbs is further compromised. Additionally, calf and/or ankle support from lithotomy stirrups may exacerbate this via compression. In the case of lengthy cases, a positive-feedback cycle of ischemia and consequent edema can develop, eventually leading to compartment syndrome or rhabdomyolysis. ${ }^{26}$ The patient may not present until postoperatively, once reperfusion injury leads to pain from compartment syndrome or rhabdomyolysis. ${ }^{27}$ These conditions are often met in extirpative robotic-assisted pelvic surgeries, and the multiple series of compartment syndrome or rhabdomyolysis following RALP as well as radical cystectomy indicates their danger. ${ }^{28-30}$ It's worth noting that rhabdomyolysis is not limited to lithotomy-based procedures, as a recent review of over 500,000 robot-assisted extirpative renal surgeries found 745 instances of postoperative rhabdomyolysis. ${ }^{31}$

A split leg table obviates the need for stirrups and theoretically addresses the problems described above; however, a study of 377 patients who underwent RALP on a split leg table found that $1.3 \%$ of patients developed lower extremity neuropathies. ${ }^{15}$ The majority were femoral nerve mononeuropathies, in comparison to peroneal neuropathies seen in lithotomy cases. There is currently no data supporting the fact that split leg table decreases the rate of compartment syndrome or rhabdomyolysis. Similarly, side docking to avoid lithotomy position may result in a trade-off in that the "elbow" of the robot could cause external compression or obscure visualization of the leg. Vigilance is important in either approach. Furthermore, patient flexibility in the hips may not accommodate the robot at all when using split leg tables. Summary statement: positioning injuries result from intraneural ischemia caused by either stetching or pressure. This can injure any nerve, but peroneal and brachial plexus injuries are the most common.

\section{Practical guidance- risk factors}

Our discussion of minimally invasive-specific positioning injuries reviewed equipment- and positioning-related risk factors, namely stirrups and Trendelenburg position. Side docking or split leg table could mitigate some of these concerns. However, there are additional factors that have been implicated, and here we will discuss several of these most salient factors to consider during minimally invasive surgery.

\section{Case duration}

Case duration correlates with positioning injuries. For example, Gelpi-Hammerschmidt et al's recent populationbased study of extirpative renal surgeries found that case length $>5$ hours significantly increased chance of rhabdomyolysis (odds ratio: $3.29, p<0.001$ ). ${ }^{31}$ A prospective study of a single-surgeon learning curve of RALP demonstrated a significant decrease in positioning injuries and postoperative creatinine kinase as operative time significantly decreased. ${ }^{32}$ Velchuru et al studied postoperative neuropathy in minimally invasive colorectal surgeries and demonstrated that those with postoperative neuropathy had significantly longer cases. ${ }^{33}$

\section{Body mass index}

Both extremes of body mass index (BMI) have been shown to increase the risk of postoperative peripheral neuropathy. Obesity has been shown to independently increase the risk of both peripheral nerve and muscular injuries, presumably from exacerbation of pressure/compression and stretch due to weight.$^{31,33,34}$ We posit that these are exacerbated in the steep Trendelenburg position. ${ }^{34}$ It is worth noting that some studies have not found BMI to correlate with injury, although these studies tended to have overall lower injury rates and may be underpowered. ${ }^{35,36}$ Low BMI conversely has been associated with increased risk of lower extremity neuropathy in the lithotomy position, presumably due to less organic padding to protect nerves, as well as brachial plexus injuries in laparoscopic rectal cases..$^{37,38}$

\section{American Society of Anesthesiologists (ASA) Physical Status Classification system}

Overall functional status was the most striking predictor noted in Mills et al's retrospective review of peripheral nerve injury in 331 patients undergoing robot-assisted urologic surgery: no ASA Class 1 patients developed injuries, while $50 \%$ of ASA Class 4 patients developed them. ${ }^{34}$ These findings were echoed by a 2013 prospective Portuguese study. ${ }^{39}$ This is likely related to factors such as malnutrition, diabetes and peripheral vascular disease, which make a patient more vulnerable to neuromuscular insults. Summary statement: a myriad of surgical team and patient-related risk factors exist, and the surgeon must recognize these additive effects and lead his or her operative team in management. 


\section{Practical guidance - prevention}

Prevention begins with awareness. At our institution, positioning injuries decreased fivefold after an interim safety analysis of the beanbag, which we attributed to increased surgical team awareness of the problem. In the previous section, we have discussed the incidence and mechanisms for positioning injuries. We will now move to discuss strategies to prevent them.

\section{Patient-modifiable factors}

For elective surgeries, optimal medical management of comorbidities such as hypertension, heart failure, peripheral vascular disease, and diabetes is prudent. Setting weight criteria can be an excellent motivator for patient behavioral changes, when the natural history of the disease does not provide a time constraint.

\section{Judicious positioning choice}

Sliding must be prevented by using materials that do not allow a patient to slip. Friction is the key to not allowing the patient to slide during the case and can be created by a variety of padding materials. The manner in which the legs are positioned in the stirrups is important. Padding around the peroneal nerve as well as minimizing high lithotomy position by not flexing at the groin will minimize compression of the femoral nerve. The shoulders should not be hyperextended nor the arms abducted. During the surgery, shorten the time in the "at-risk" position when possible. For example, during a robotic cystectomy, reposition the patient by taking out of stirrups and placing supine when the extirpative portion is complete and the ileal conduit is being created.

\section{Intraoperative}

The entire team must be cognizant of changes in the positioning and factors that can exacerbate risk. The anesthesiologist should employ judicious use of intravenous crystalloid to minimize the risk of neural edema. The surgeon should use the least amount of pneumoperitoneum needed to safely perform the surgery and avoid overly steep Trendelenburg position when possible. The nursing team should monitor the robot arms and trocars as the surgeon is working and not hesitate to speak up if contact is occurring. Second timeouts involving rechecking patient positioning have been proposed for cases lasting longer than $4-5$ hours. ${ }^{40}$ Assessing capillary refill with Doppler or utilizing evoked potential monitoring has been described. ${ }^{41,42}$ Table 2 summarizes in pictorial form these useful safety tenets.

\section{Market forces}

Although reported incidence rates for positioning injuries are low at $<5 \%$, there appears to be a growing market for equipment aimed at eliminating positioning injuries in minimally invasive surgery. Our program has received increasing numbers of advertisements from companies offering such devices. Allen stirrups were an early improvement over traditional candy-cane stirrups. One program reported complete elimination of postoperative peripheral nerve injuries following the introduction of Allen stirrups and beanbags. ${ }^{36}$ The avoidance of "slippage" has been tackled by two different methodologies. First, friction coefficient pads, gel pads, and restraint straps are being marketed to make it impossible for the patient to slide during the case. ${ }^{43-45}$ Second, vacuum devices that envelop the length of the patient are being modified to stop movement during the Trendelenburg portion of the surgery. ${ }^{46}$ In 2016, the Massachusetts General Hospital developed an in-house surgical safety board aimed at minimizing contact pressures and preventing slippage. This safety board showed good results in 16 patients prospectively trialed over surgeries averaging 3.5 hours in patients with a mean BMI of $27 .{ }^{47}$ Finally, the latest in this wave of innovations to

Table 2 Safety tenets

\begin{tabular}{lll}
\hline Patient-modifiable & Optimize chronic medical condition & \\
Encourage weight loss & No dorsal flexion or lateral extension \\
& Keep the head/neck neutral & Friction materials under patient \\
Svoid sliding & Minimize abduction or extension \\
Surgeon & Keep arms at sides & Least amount of pneumopertioneum \\
& Minimize pressure & Least amount of Trendelenburg necessary \\
& Reduce risk of sliding & Side docking \\
Intraoperative & Minimize operative time efficient & \\
& Somatosensory potentials tracking & \\
& Doppler or other to monitor perfusion & \\
& Judicious fluid administration & \\
& Nursing to reassess position throughout the surgery & \\
\hline
\end{tabular}


minimize positioning injury is neuromodulation. Attempts are being made to create user friendly, noninvasive monitoring devices that can detect compression or stretching of the nerves. Ideally, early identification of stretch would allow for repositioning of the limb in question. ${ }^{48}$ Summary statement: prevention of injuries can occur if patients are encouraged to lose weight (if disease process would accommodate), the intraoperative team prevents slippage or hyperextension and surgeon minimizes surgery duration, including conversion to open if necessary.

\section{Conclusion}

The incidence of positioning injuries in minimally invasive surgery appears to be higher than previously appreciated, perhaps due to heightened awareness. The development of numerous medical devices to mitigate these injuries suggests that not all of these neurologic complaints resolve postoperatively. Surgeons should discuss the potential for these complications with their patients, and operative teams should take steps to minimize risk factors.

\section{Disclosure}

Dr Krupski is a subinvestigator for studies/trials under the National Cancer Institute, American Cancer Society, FKD, and Argos. The authors report no conflicts of interest in this work.

\section{References}

1. Kroll DA, Caplan RA, Posner K, Ward RJ, Cheney FW. Nerve injury associated with anesthesia. Anesthesiology. 1990;73(2):202-207.

2. Cheney FW, Domino KB, Caplan RA, Posner KL. Nerve injury associated with anesthesia: a closed claims analysis. Anesthesiology. 1999; 90(4):1062-1069.

3. Irvin W, Andersen W, Taylor P, Rice L. Minimizing the risk of neurologic injury in gynecologic surgery. Obstet Gynecol. 2004;103(2):374-382.

4. Romanowski L, Reich H, McGlynn F. Brachial plexus neuropathies after advanced laparoscopic surgery. Fertil Steril. 1993;60(4):729-732.

5. Nuzzi R, Tridico F. Ocular complications in laparoscopic surgery: review of existing literature and possible prevention and treatment. Semin Ophthalmol. 2016;31(6):584-592.

6. Winfree CJ, Kline DG. Intraoperative positioning nerve injuries. Surg Neurol. 2005;63(1):5-18.

7. Ochoa J, Fowler TJ, Gilliatt RW. Anatomical changes in peripheral nerves compressed by a pneumatic tourniquet. JAnat. 1972;113(Pt 3): $433-455$

8. Stewart JD. Focal Peripheral Neuropathies. 3rd ed. Philadelphia, PA: lippincott Williams \& Wilkins; 2000:11-35.

9. Tong C, Olympio M, Bodin S, Edwards A, Hemal A. Leg muscle hypoxia and RALUS. In: Abstracts of the 2010Annual Meeting of the ASA; 2010 October 16-20. San Diego, CA; 2010: A194. Available from: http:// www.asaabstracts.com/strands/asaabstracts/abstract.htm $\% 20 \% 20$;jse ssionid=965E735EE570DD53F26E5E695994068C year=2010\&inde $\mathrm{x}=15$ \&absnum $=841$. Accessed May 3, 2017.

10. Peters P, Baker SR, Leopold PW, Taub NA, Burnand KG. Compartment syndrome following prolonged pelvic surgery. Br J Surg. 1994; 81(8):1128-1131.
11. Martin JT. Compartment syndromes: concepts and perspectives for the anesthesiologist. Anesth Analg. 1992;75(2):275-283.

12. Ficko Z, Koo K, Hyams ES.High tech or high risk? An analysis of media reports about robotic surgery. J Robotic Surg. Epub 2016 Oct 24.

13. Aggarwal R, Hance J, Darzi A. Robotics and surgery: a long-term relationship? Int J Surg. 2004;2(2):106-109.

14. Orvieto MA, Marchetti P, Castillo OA, et al. Robotic technologies in surgical oncology training and practice. Surg Oncol. 2011;20(3):203-209.

15. Koç G, Tazeh NN, Joudi FN, Winfield HN, Tracy CR, Brown JA. Lower extremity neuropathies after robot-assisted laparoscopic prostatectomy on a split-leg table. J Endourol. 2012;26(8):1026-1029.

16. Shveiky D, Aseff JN, Iglesia CB. Brachial plexus injury after laparoscopic and robotic surgery. J Minim Invasive Gynecol. 2010;17(4): 414-420.

17. Jackson L, Keats AS. Mechanism of brachial plexus palsy following anesthesia. Anesthesiology. 1965;26(2):190-194.

18. Hayreh SS. Posterior ischaemic optic neuropathy: clinical features, pathogenesis, and management. Eye (Lond). 2004;18(11):1188-1206.

19. Weber ED, Colyer MH, Lesser RL, Subramanian PS. Posterior ischemic optic neuropathy after minimally invasive prostatectomy. J Neuroophthalmol. 2007;27(4):285-287.

20. Awad H, Santilli S, Ohr M, et al. The effects of steep trendelenburgpositioning on intraocular pressure during robotic radical prostatectomy. Anesth Analg. 2009;109(2):473-478.

21. Kan KM, Brown SE, Gainsburg DM. Ocular complications in roboticassisted prostatectomy: a review of pathophysiology and prevention. Minerva Anestesiol. 2015;81(5):557-566.

22. Hoshikawa Y, Tsutsumi N, Ohkoshi K, et al. The effect of steep Trendelenburg positioning on intraocular pressure and visual function during robotic-assisted radical prostatectomy. Br J Ophthalmol. 2014;98(3):305-308.

23. Warner MA, Warner DO, Harper CM, Schroeder DR, Maxson PM. Lower extremity neuropathies associated with lithotomy positions. Anesthesiology. 2000;93(4):938-942.

24. Akhavan A, Gainsburg DM, Stock JA. Complications associated with patient positioning in urologic surgery. Urology. 2010;76(6):1309-1316.

25. Litwiller JP, Wells REJr, Halliwill JR, Carmichael SW, Warner MA. Effect of lithotomy positions on strain of the obturator and lateral femoral cutaneous nerves. Clin Anat. 2004;17(1):45-49.

26. Raza A, Byrne D, Townell N. Lower limb (well leg) compartment syndrome after urological pelvic surgery. J Urol. 2004;171(1):5-11.

27. Walker PM. Ischemia/reperfusion injury in skeletal muscle. Ann Vasc Surg. 1991;5(4):399-402.

28. Pridgeon S, Bishop CV, Adshead J. Lower limb compartment syndrome as a complication of robot-assisted radical prostatectomy: the UK experience. BJU Int. 2013;112(4):485-488.

29. Wen T, Deibert CM, Siringo FS, Spencer BA. Positioning-related complications of minimally invasive radical prostatectomies. J Endourol. 2014;28(6):660-667.

30. Galyon SW, Richards KA, Pettus JA, Bodin SG. Three-limb compartment syndrome and rhabdomyolysis after robotic cystoprostatectomy. J ClinAnesth. 2011;23(1):75-78.

31. Gelpi-Hammerschmidt F, Tinay I, Allard CB, et al. The contemporary incidence and sequelae of rhabdomyolysisfollowing extirpative renal surgery: apopulation based analysis. J Urol. 2016;195(2):399-405.

32. Di Pierro GB, Wirth JG, Ferrari M, Danuser H, Mattei A. Impact of a single-surgeon learning curve on complications, positioning injuries, and renal function in patients undergoing robot-assisted radical prostatectomy and extended pelvic lymph node dissection. Urology. 2014; 84(5):1106-1111.

33. Velchuru VR, Domajnko B, deSouza A, et al. Obesity increases the risk of postoperative peripheral neuropathy after minimally invasive colon and rectal surgery. Dis Colon Rectum. 2014;57(2):187-193.

34. Mills JT, Burris MB, Warburton DJ, Conaway MR, Schenkman NS, Krupski TL. Positioning injuries associated with robotic assisted urological surgery. J Urol. 2013;190(2):580-584. 
35. Ulm MA, Fleming ND, Rallapali V, et al. Position-related injury is uncommon in robotic gynecologic surgery. Gynecol Oncol. 2014;135(3): 534-538.

36. Navarro-Vicente F, García-Granero A, Frasson M, et al. Prospective evaluation of intraoperative peripheral nerve injury in colorectal surgery. Colorectal Dis. 2012;14(3):382-385.

37. Eteuati J,Hiscock R, Hastie I, Hayes I, Jones I. Brachial plexopathy in laparoscopic-assisted rectal surgery: a case series. Tech Coloproctol. 2013;17(3): 293-297.

38. Warner MA, Martin JT, Schroeder DR, Offord KP, Chute CG. Lowerextremity motor neuropathy associated with surgery performed on patients in a lithotomy position. Anesthesiology. 1994;81(1):6-12.

39. Menezes S, Rodrigues R, Tranquada R, Müller S, Gama K, Manso T. Lesões resultantes do posicionamento para cirurgia: incidência e fatores de risco. [Injuries resulting from positioning for surgery: incidence and risk factors]. Acta Med Port. 2013;26(1):12-16. Portuguese.

40. Song JB, Vemana G, Mobley JM, Bhayani SB. The second "time-out": a surgical safety checklist for lengthy robotic surgeries. Patient Saf Surg. 2013;7(1):19.

41. Hickey C, Gugino LD, Aglio LS, Mark JB, Son SL, Maddi R. Intraoperative somatosensory evoked potential monitoring predicts peripheral nerve injury during cardiac surgery. Anesthesiology. 1993;78(1):29-35.

42. Falabella A, Moore Jeffries E, Sullivan MJ, Nelson R, Lew M. Cardiac function during steep Trendelenburg position and $\mathrm{CO} 2$ pneumoperitoneum for robotic-assisted prostatectomy: a trans-oesophageal Doppler probe study. Int J Med Robot. 2007;3(4):312-315.

43. Greenberg JA. The pink pad-Pigazzipatient positioning system ${ }^{\mathrm{TM}}$. Rev Obstet Gynecol. 2013;6(2):97-98.

44. Wechter ME, Kho RM, Chen AH, Magrina JF, Pettit PD. Preventing slide in Trendelenburg position: randomized trial comparing foam and gel pads. J Robot Surg. 2013;7(3):267-271.
45. Deane LA, Lee HJ, Box GN, et al. Third prize: flank position is associated with higher skin-to-surface interface pressures in men versus women: implications for laparoscopic renal surgery and the risk of rhabdomyolysis. J Endourol. 2008;22(6):1147-1152.

46. Allen Hug-U-Vac Steep Trend Positioner. Allen Medical Systems Web site. Available from: http:/www.allenmedical.com/shop/gyn--uro--lap/ gyn--uro--lap-products/item/allen-hug-u-vac-steep-trend-positioner. Accessed December 18, 2016.

47. Talab SS, Elmi A, Sarma J, Barrisford GW, Tabatabaei S. Safety and effectiveness of SAF-R, a novel patient positioning device for robot-assisted pelvic surgery in Trendelenburgposition. J Endourol. 2016;30(3):286-292.

48. Safeofsurgical.com/device [homepage on the Internet]. SafeOp Surgical, Inc.; c2012-2016. Available from: http://safeopsurgical.com/. Accessed December 18, 2016.

49. Bohrer JC, Walters MD, Park A, Polston D, Barber MD. Pelvic nerve injury following gynecologic surgery: a prospective cohort study. $\mathrm{Am}$ J Obstet Gynecol. 2009;201(5):531.e1-e7.

50. Wolf JS Jr, Marcovich R, Gill IS, et al. Survey of neuromuscular injuries to the patient and surgeon during urologic laparoscopic surgery. Urology. 2000;55(6):831-836.

51. Jeong J, Choi EY, Kim IY. Clavien classification of complications after the initial series of robot-assisted radical prostatectomy: the Cancer Institute of New Jersey/Robert Wood Johnson Medical School Experience. J Endourol. 2010;24(9):1457-1461.

52. Mattei A, Di Pierro GB, Rafeld V, Konrad C, Beutler J, Danuser H. Positioning injury, rhabdomyolysis, and serum creatinekinase-concentration course in patients undergoing robot-assisted radical prostatectomy and extended pelvic lymph node dissection. J Endourol. 2013;27(1): $45-51$.
Robotic Surgery: Research and Reviews

\section{Publish your work in this journal}

Robotic Surgery: Research and Reviews is an international, peer reviewed, open access, online journal publishing original research, commentaries, reports, and reviews on the theory, use and application of robotics in surgical interventions. Articles on the use of supervisory-controlled robotic systems, telesurgical devices, and shared-control systems are

\section{Dovepress}

invited. The manuscript management system is completely online and includes a very quick and fair peer review system, which is all easy to use. Visit http://www.dovepress.com/testimonials.php to read real quotes from published authors. 